\title{
Shape discrimination and transfer in the California sea lion'
}

RONALD J. SCHUSTERMAN AND THOMAS THOMAS ${ }^{2}$

STANFORD RESEARCH INSTITUTE, MENLO PARK, CALIFORNIA

Two sea lions (Zalophus californianus) were trained under water to discriminate stimulus figures differing in shape. Each of 12 problems was immediately followed by a transfer test in which either positive, negative or both shapes underwent changes in orientation of $45^{\circ}, 90^{\circ}$ or $180^{\circ}$. An efficient learning set was formed by one of the animals and both animals evidenced considerable or perfect transfer on most of the problems.

Investigation of the underwater visual shape discrimination of the bottlenose dolphin, Tursiops truncatus, indicates that these marine mammals have rather good shape discrimination (Kellogg \& Rice, 1963). Furthermore, such discriminations by the dolphin are readily transferred when either the positive or negative member of the original stimulus pair is changed in orientation. Schusterman, Kellogg, \& Rice (1965) have reported accurate size discrimination by the California sea lion under water, and Schusterman (1966) has shown that these animals quickly form an efficient discriminationreversal learning set. The present preliminary investigation examines the visual discrimination and transfer of shapes by the California sea lion, Zalophus californianus.

Method

The Ss were two feral California sea lions: a male (Sam) and female (Bibi), approximately 3-4 yrs. old at the time this investigation was undertaken. Both Ss had perfected a cut-out triangle-circle discrimination just prior to the present study. However, Bibi had previously received training on a serial reversal task with a single stimulus pair, averaging approximately nine errors per reversal problem at the end of 60 problems (Schusterman, 1966), while Sam had received no other type of visual discrimination training.

All testing was conducted in an oval tank constructed of redwood, painted white and measuring $15 \mathrm{ft}$. $x 30 \mathrm{ft}$. and $6 \mathrm{ft}$. deep. The testing conditions and apparatus have already been described in detail (Schusterman et $a 1,1965$ ). The Ss had been previously trained to remain almost motionless at a starting position 16 to 20 $\mathrm{ft}$. in front of a testing platform until they were signaled to approach by the sound of the stimulus display being lowered into the water. The S's task was to strike one of two target stimuli in order to obtain a small piece of herring. A perpendicular divider made of chicken wire projected $4 \mathrm{ft}$. outward between the stimulus targets and all the way down to the floor of the tank, thus preventing Ss from swimming laterally from one target to another. It should be noted that a hydrophone and speaker-amplifier system were used to monitor the underwater vocalizations of these animals (Schusterman, 1966; Schusterman \& Feinstein, 1965) throughout the entire study.

The stimulus shapes and the sequence in which the problems were presented are shown in Fig. 1. The shapes were 7 in. $^{2}$ in area and were painted black against a white $5 \times 5$ in. square. Although both Ss were trained on each original stimulus pair followed immediately by a transfer test, the procedures differed for the two Ss. Whereas the preference method (without differential reinforcement) was used for Bibi's transfer tests, the relearning method (with differential reinforcement as employed by Kellogg \& Rice, 1963) was used for Sam's transfer tests. For numerous reasons, the former procedure is considered much more appropriate for testing stimulus equivalence or transfer (Sutherland, 1961). Thus, after learning each original discrimination to a criterion of 18 correct of 20 consecutive responses, Sam relearned the transfer pair to the same criterion. Bibi, however, following original learning and 20 over-learning trials, received 20 additional retraining trials intermixed with 20 preference trials in which responses to either stimulus pattern were reinforced. The Ss received an original problem and a transfer test at each session unless criterion on the original problem was not attained. In that case, the session was terminated after 100 trials. Throughout the entire experiment, a noncorrection technique was used and position of the stimulus patterns was an irrelevant cue.
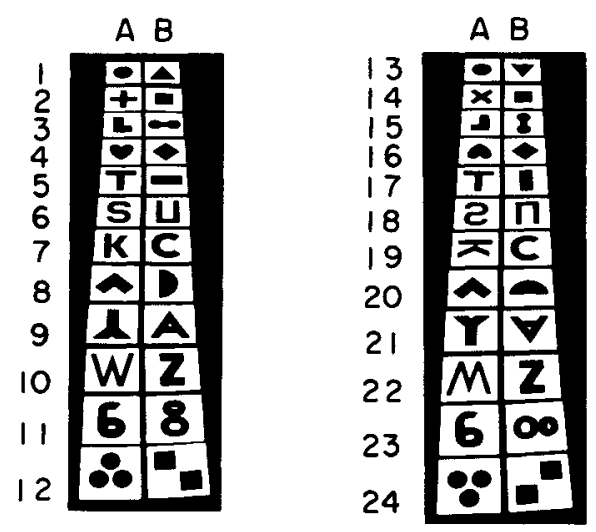

Fig. 1. Photograph of the stimulus patterns. The first 12 pairs were the original training patterns and pairs $13-24$ were the transfer patterns. Column $A$ designates the positive shapes for sea lion Sam and column $B$ designates the positive shapes for sea lion Bibi on original training only. Note that for each of four of the original shapes, either positive, negative or both shapes changed orientation during transfer tests. 


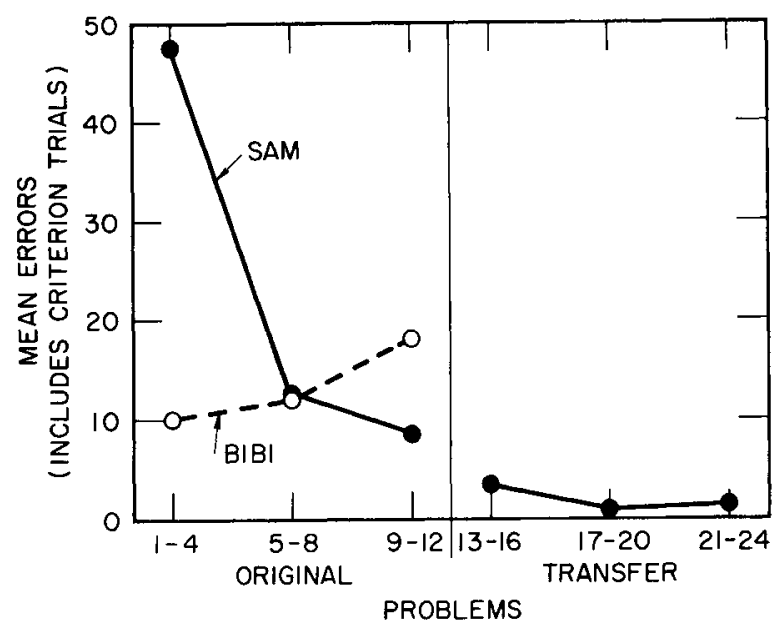

Fig. 2. Interproblem performance curves.

\section{Results}

The interproblem performance curves for the original problems are presented in the left panel of Fig. 2 and are self-explanatory. Results from Sam's transfer tests presented in the right panel of Fig. 2 show that this $\mathrm{S}$ demonstrated considerable transfer from the original problems.

Bibi's transfer data are presented in Table 1. The formula for the transfer index developed by Sutherland (1961) is $\frac{T-50}{0-50}$, where 0 is the percentage of correct responses given on the retraining trials and $T$ is the percentage of times that the transfer shape is treated as equivalent to one of the original training shapes. Inspection of the table reveals considerable or perfect transfer on 9 of the 12 stimulus pairs. It appears to make only a slight difference as to whether the,+- , or both original shapes change orientation. Furthermore, the degree of transfer seems not to be affected by whether the

Table 1.

Performance of sea lion Bibi on original learning and transfer.

\begin{tabular}{cccccc} 
Stimulus Pair* & $\begin{array}{c}\text { Original } \\
\text { Learning } \\
\text { (Errors) }\end{array}$ & \multicolumn{2}{c}{$\begin{array}{c}\text { Transfer Tests } \\
\text { \% Responses }\end{array}$} & & \multicolumn{2}{c}{$\begin{array}{l}\text { Transfer } \\
\text { Retraining }\end{array}$} \\
\hline$I_{+}$ & 12 & 95 & 95 & $<.01$ & 1.00 \\
$5+$ & 4 & 100 & 70 & $>.05$ & .40 \\
$8+$ & 13 & 100 & 95 & $<.01$ & .90 \\
$11+$ & 35 & 45 & 15 & $>.05$ & -- \\
$2-$ & 1 & 100 & 100 & $<.01$ & 1.00 \\
$4-$ & 23 & 100 & 85 & $<.01$ & .70 \\
$7-$ & 30 & 100 & 100 & $<.01$ & 1.00 \\
$10-$ & 8 & 100 & 100 & $<.01$ & 1.00 \\
3 both & 5 & 100 & 100 & $<.01$ & 1.00 \\
6 both & 1 & 100 & 100 & $<.01$ & 1.00 \\
9 both & 29 & 100 & 55 & $>.05$ & .10 \\
12 both & 1 & 100 & 80 & $<.01$ & .60 \\
\hline
\end{tabular}

* The designations of +, -, or both indicate the reinforcement values of the original shapes which underwent change during the transfer tests, (see Fig. 1).

** Refers to responses to column-B shapes of stimulus pairs 13 - 24 shown in Fig. 1. shapes undergo changes in orientation of $45^{\circ}, 90^{\circ}$, or $180^{\circ}$. It should be noted that although Sam remained silent, Bibi increased the frequency with which she emitted clicking sounds during training and test trials.

\section{Discussion}

Since the sensory and brain structures of the California sea lion and the bottlenose dolphin are quite different, it is interesting to compare these two marine mammals on a similar behavioral task. Comparison of the present results on Zalophus with those of Kellogg \& Rice (1963) on Tursiops reveals remarkable similarities in their ability to discriminate and classify a number of different shapes. Although there is no comparable data as yet available on any of the cetaceans or on other pinniped forms, Sam's performance suggests that Zalophus forms a discrimination learning set at least as efficiently as do the more terrestrial carnivores.

In contrast to Sam's performance on the first four original problems, Bibi's performance seemed to be considerably facilitated by previous serial discrimination-reversal training. Although the data were obtained from only two Ss and were not very extensive, they do suggest that the California sea lion, like the chimpanzee (Schusterman, 1964) and the rhesus monkey (Warren, in press) may be capable of demonstrating significant positive transfer from successive discrimination-reversal training to the learning of multiple discriminations.

Finally, observations of California sea lions and harbor seals swimming upside down and on their side during a variety of discrimination tasks suggest that the visual perceptual organization of these marine mammals may be quite different from that of more terrestrial mammalian forms. Results from the present experiment tend to support this suggestion.

\section{References}

Kellogg, W. N., \& Rice, C. E. Visual problem-solving in a bottlenose dolphin. Science, 1964, 143, 1052-1055.

Schusterman, R. J. Successive discrimination-reversal training and multiple discrimination training in one-trial learning by chimpanzees. J. comp. physiol. Psychol, 1964, 58, 153-156.

Schusterman, R. J. Successive discrimination-reversal learning with and without errors by the California sea lion. J. exp. Anal. Behav., 1966 (under review).

Schusterman, R. J. Underwater click vocalizations by a California sea lion: Effects of visibility. Psychol. Rec., 1966, 16, in press.

Schusterman, R. J., \& Feinstein, S. H. Shaping and discriminative control of underwater click vocalizations in a California sea lion. Science, $1965,150,1743-1744$.

Schusterman, R. J., Kellogg, W. N., \& Rice, C. E. Underwater visual discrimination by the California sea lion. Science, 1965 , 147, 1594-1596.

Sutherland, N. S. Shape discrimination by animals. Exp. Psychol. Soc. Monogr., No. 1. Cambridge, England: W. Heffer \& Sons, 1961.

Warren, J. M. Reversal learning and the formation of learning sets by cats and rhesus monkeys. J. comp. physiol. Psychol.,1966, in press.

\section{Notes}

1. Supported by NSF Grant GB-1437.

2. Now at Colorado State University. 